\title{
Seismic stability of reinforced-soil wall by pseudo-dynamic method
}

\author{
S. S. Nimbalkar ${ }^{1}$, D. Choudhury ${ }^{2}$ and J. N. Mandal ${ }^{3}$ \\ ${ }^{1}$ Research Scholar, Department of Civil Engineering, Indian Institute of Technology Bombay, Powai, \\ Mumbai 400 076, India, Telephone: +9193267 12190, Telefax: +91222576 7302, \\ E-mail: sanjay_nimbalkar@iitb.ac.in \\ ${ }^{2}$ Assistant Professor, Department of Civil Engineering, Indian Institute of Technology Bombay, Powai, \\ Mumbai 400 076, India, Telephone: +91 222576 7335, Telefax: +91 222576 7302, \\ E-mail:dc@civil.iitb.ac.in \\ ${ }^{3}$ Professor, Department of Civil Engineering, Indian Institute of Technology Bombay, Powai, Mumbai \\ 400 076, India, Telephone: +91222576 7328, Telefax: +91222576 7302, \\ E-mail:cejnm@civil.iitb.ac.in
}

Received 5 December 2005, revised 10 March 2006, accepted 28 March 2006

\begin{abstract}
Determination of the internal stability of reinforced soil walls under earthquake conditions is an important part of seismic design. The horizontal method of slices is used for determining internal stability or for tieback analysis of the reinforced soil wall. A pseudo-dynamic method is adopted in the present analysis, which considers the effect of phase difference in both the shear and primary waves travelling through the backfill due to seismic excitation. Reinforced soil walls with cohesionless backfill material have been considered in the analysis. Results are presented in graphical and tabular form to show the required tensile force and length of geosynthetic reinforcement to maintain the stability of the reinforced soil wall under seismic conditions. The effects of variation of parameters such as soil friction angle and horizontal and vertical seismic accelerations on the stability of the reinforced soil wall have been studied. With an increase of seismic accelerations in both the horizontal and vertical directions the stability of the reinforced soil wall decreases significantly, and thus greater strength and length of the geosynthetic reinforcement are required to maintain stability of the wall. The seismic vertical acceleration in an upward direction gives higher values of the required geosynthetic tensile strength, and the seismic vertical acceleration in the downward direction yields higher values of the length of geosynthetic reinforcement. Comparisons of the present results with available pseudo-static results are shown, and the limitations of the pseudo-static results are highlighted.
\end{abstract}

KEYWORDS: Geosynthetics, Earthquake, Reinforced soil, Retaining wall, Design, Internal stability, Modelling

REFERENCE: Nimbalkar, S. S., Choudhury, D. \& Mandal, J. N. (2006). Seismic stability of reinforced-soil wall by pseudo-dynamic method. Geosynthetics International, 13, No. 3, 111-119

\section{INTRODUCTION}

Numerous methods are available for the seismic design of reinforced soil walls based on the pseudo-static method of analysis. The pioneering work on earthquake-induced lateral earth pressure under active and passive conditions acting on a retaining wall was reported by Okabe (1926) and Mononobe and Matsuo (1929). This pseudo-static approach, following Coulomb's earth pressure analysis under static conditions, is known as the Mononobe-Okabe method (Kramer 1996). The Mononobe-Okabe method can also be extended to the seismic analysis of reinforced soil walls. Ling et al. (1997) have proposed seismic design procedures based on pseudo-static limit equilibrium analysis, which considers only the horizontal seismic acceleration in the soil medium. Ling and Leshchinsky (1998) have also studied the effect of pseudo-static vertical seismic acceleration on the seismic design of geosynthetic-reinforced soil walls. Shahgholi et al. (2001) used a horizontal slice method to analyse and investigate the seismic stability of reinforced soil walls. Kramer and Paulsen (2004) carried out seismic performance evaluation of reinforced slopes. El-Emam and Bathurst (2005) analysed the facing contribution to seismic response of reduced-scale reinforced soil walls subjected to a stepped amplitude sinusoidal base input acceleration. Huang and Wang (2005) presented a pseudo-static-based approach for evaluating the mechanical effects of facing components on the seismic displacement of reinforced soil walls backfilled with cohesionless soils. 
However, all the above methods are based on the pseudo-static method of analysis, which considers the dynamic nature of earthquake loading in a very approximate way (Kramer 1996). These methods do not consider the effects of time and body waves travelling through the soil during the earthquake. Recently, Ling et al. (2005) conducted large-scale shaking table tests on modular-block reinforced soil-retaining walls. As proposed by Steedman and Zeng (1990), the phase difference due to finite shear wave propagation through a reinforced soil wall can be considered using a relatively new method, called the pseudo-dynamic method in this paper. Recently, Choudhury and Nimbalkar (2006) proposed a theory to compute the seismic active earth pressure by pseudodynamic method by considering both the shear and the primary waves propagating through the soil with variation in time by considering harmonic horizontal and vertical seismic accelerations. Choudhury and Nimbalkar (2005) also developed the theory to estimate the seismic passive earth pressure using the pseudo-dynamic approach. Here the authors considered both the shear and primary waves propagating through the soil with variation in time by considering harmonic horizontal and vertical seismic accelerations. However, the work by Choudhury and Nimbalkar $(2005,2006)$ was limited to un-reinforced rigid retaining walls. Hence in this paper an attempt has been made to investigate the stability of reinforced soil walls under seismic conditions by using the pseudo-dynamic method, which considers the time and phase change effects due to shear and primary waves propagating vertically through reinforced backfill, along with other seismic input parameters.

\section{METHOD OF ANALYSIS}

\subsection{Background}

The reinforcement in geosynthetic wall structures must be designed with adequate strength and length to resist different possible modes of failure, namely tieback, compound and pullout failure. The required geosynthetic tensile force is determined through tieback (internal stability) analysis, and the required geosynthetic length is obtained by considering potential rotational failures, extending both within and beyond the reinforced zone (compound failure) (Koerner 1994). For the seismic case, the internal stability analysis for reinforced soil walls can be carried out using pseudo-static forces as given by Kramer (1996).

In the present study, the pseudo-dynamic method considers the finite shear and primary wave velocities in the analysis. It is assumed that the shear modulus is constant with depth through the backfill, and that only the phase and not the amplitude of the acceleration is varying.

Consider a reinforced soil wall of height $H$ with slope angle $\beta$, constructed of dry cohesionless free-draining soil as shown in Figure 1. Under earthquake condition, the shear wave velocity $V_{\mathrm{s}}=(G / \rho)^{1 / 2}$ and primary wave velocity $V_{\mathrm{p}}=[G(2-2 v) / \rho(1-2 v)]^{1 / 2}$ are assumed to act within the reinforced soil structure. For most geological materials, $V_{\mathrm{p}} / V_{\mathrm{s}}=1.87$ (Das 1993) is considered. The

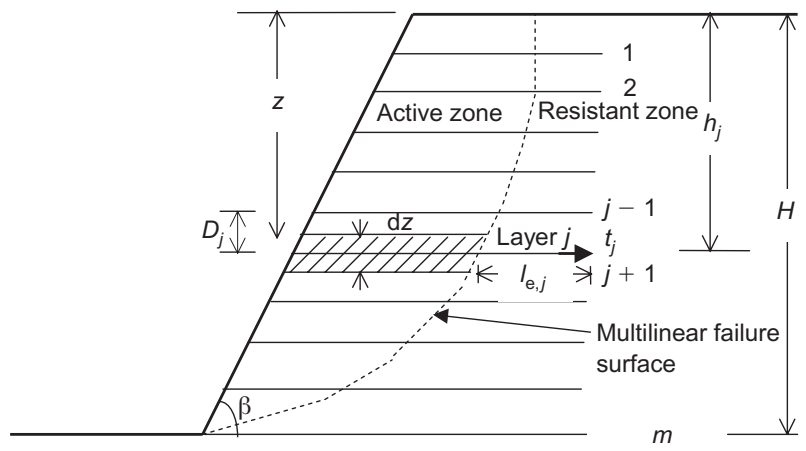

Figure 1. Configuration of model reinforced soil wall considered in the analysis

period of lateral shaking, $T=2 \pi / \omega=4 H / V_{\mathrm{s}}$ (Kramer 1996), is considered in the analysis. In the present analysis, it is assumed that both the horizontal and vertical vibrations, with accelerations $a_{\mathrm{h}}$ and $a_{\mathrm{v}}$, respectively, start at exactly the same time, and there is no phase shift between these two vibrations, thus giving the critical condition for design. The tensile force in the geosynthetic layer is considered to act horizontally, because its inclination has little effect on the results of analysis when cohesionless soils are used (Leshchinsky and Boedeker 1989; Wright and Duncan 1991). In the present method, the failure surface is assumed as multilinear, in which a number of failure planes are considered to identify the critical design criteria.

In the present method, the seismic accelerations acting on the reinforced-soil wall are considered as harmonic sinusoidal accelerations, which is one of the limitations of the pseudo-dynamic method as originally proposed by Steedman and Zeng (1990).

\subsection{Calculation of pseudo-dynamic inertia forces}

If the base is subjected to harmonic horizontal and vertical seismic accelerations of amplitudes $a_{\mathrm{h}}$ and $a_{\mathrm{v}}$, the accelerations at depth $z$ below the top of the wall can be expressed as

$$
\begin{aligned}
& a_{\mathrm{h}}(z, t)=a_{\mathrm{h}} \sin \omega\left(t-\frac{H-z}{V_{\mathrm{s}}}\right) \\
& a_{\mathrm{v}}(z, t)=a_{\mathrm{v}} \sin \omega\left(t-\frac{H-z}{V_{\mathrm{p}}}\right)
\end{aligned}
$$

For a thin elemental slice of thickness $\mathrm{d} z$ at depth $z$, as shown in Figures 1 and 2, the mass of the elemental $i$ th slice is given by

$$
m_{i}(z)=\frac{\gamma}{g} \frac{H-z}{\tan \alpha_{i}} \mathrm{~d} z
$$

The weight of the elemental $i$ th slice is

$$
W_{i}=\gamma \mathrm{d} z\left(\frac{l_{j}+l_{j+1}}{2}\right)
$$

The total horizontal inertia force $q_{\mathrm{h} i}$ acting on the $i$ th slice can be expressed as

$$
q_{\mathrm{h} i}=m_{i}(z) \cdot a_{\mathrm{h}}(z, t)
$$




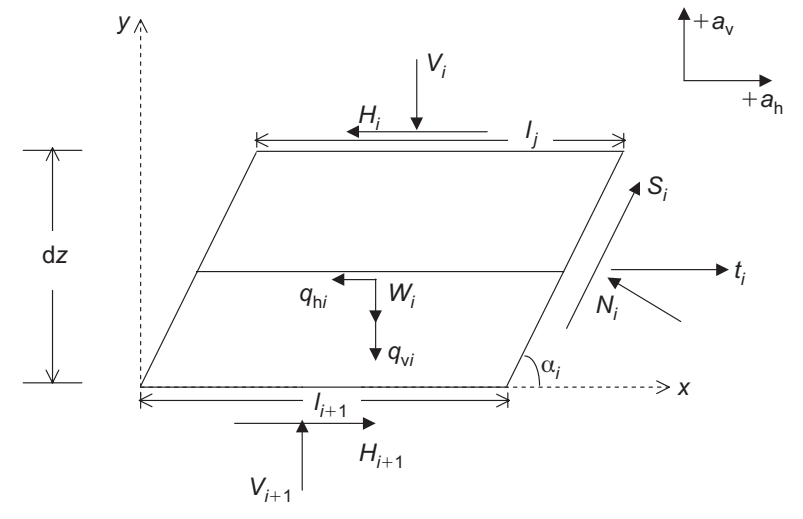

Figure 2. Forces acting on single horizontal elemental slice containing reinforcement

The total horizontal inertia force $Q_{\mathrm{h}}$ acting on the reinforced soil wall can be expressed as

$$
\begin{aligned}
Q_{\mathrm{h}} & =\int_{0}^{H} q_{\mathrm{h} i} \mathrm{~d} z=\int_{0}^{H} m_{i}(z) \cdot a_{\mathrm{h}}(z, t) \mathrm{d} z \\
& =\frac{\lambda \gamma k_{\mathrm{h}}}{4 \pi^{2} \tan \alpha_{i}}[2 \pi H \cos \omega \zeta+\lambda(\sin \omega \zeta-\sin \omega t)]
\end{aligned}
$$

Again, the total vertical inertia force $q_{\mathrm{v} i}$ acting on the $i$ th slice can be expressed as

$$
q_{\mathrm{v} i}=m_{i}(z) \cdot a_{\mathrm{v}}(z, t)
$$

The total vertical inertia force $Q_{\mathrm{v}}$ acting on the reinforced soil wall can be expressed as

$$
\begin{aligned}
Q_{\mathrm{v}} & =\int_{0}^{H} q_{\mathrm{v} i} \mathrm{~d} z=\int_{0}^{H} m_{i}(z) \cdot a_{\mathrm{v}}(z, t) \mathrm{d} z \\
& =\frac{\eta \gamma k_{\mathrm{v}}}{4 \pi^{2} \tan \alpha_{i}}[2 \pi H \cos \omega \psi+\eta(\sin \omega \psi-\sin \omega t)]
\end{aligned}
$$

where $\lambda=T V_{\mathrm{s}}$ is the wavelength of the vertically propagating shear wave, $\eta=T V_{\mathrm{p}}$ is the wavelength of the vertically propagating primary wave, $\zeta=t-H / V_{\mathrm{s}}$ and $\psi=t-H / V_{\mathrm{p}}$ Only the critical directions of $q_{\mathrm{h} i}$ and $q_{\mathrm{v} i}$ acting on the elemental slice are considered, as shown in Figure 2: that is, the vertical seismic inertia force $q_{\mathrm{v} i}$ acting in the upward direction is considered in calculating the geosynthetic length required to resist tie-back, compound and pullout failure. Similarly, the vertical seismic inertia force $q_{\mathrm{v} i}$ ) acting in the downward direction is considered in determining the required geosynthetic tensile reinforcement (Ling and Leshchinsky 1998).

The special case of a rigid wedge is given, in the limit, as

$$
\begin{aligned}
& \lim _{V_{\mathrm{s}} \rightarrow \infty}\left(Q_{\mathrm{h}}\right)_{\max }=\frac{\gamma H^{2} a_{\mathrm{h}}}{2 g \tan \alpha}=\frac{a_{\mathrm{h}}}{g} W=k_{\mathrm{h}} W \\
& \lim _{V_{\mathrm{P}} \rightarrow \infty}\left(Q_{\mathrm{v}}\right)_{\max }=\frac{\gamma H^{2} a_{\mathrm{v}}}{2 g \tan \alpha}=\frac{a_{\mathrm{v}}}{g} W=k_{\mathrm{v}} W
\end{aligned}
$$

which is equivalent to the pseudo-static forces assumed in the Mononobe-Okabe method without considering any phase change in the body waves travelling through the soil medium.

\subsection{Tieback or internal stability analysis}

The required tensile strength and minimum length of each geosynthetic reinforcement layer are determined from the pseudo-dynamic method of analysis using a multilinear failure surface. A horizontal method of slices is used in this analysis. The following assumptions are made in the present analysis.

- The vertical stress on an element in the soil mass is equal to the overburden pressure.

- The factor of safety (FS) is equal to the ratio of the available shear resistance to the required shear resistance along the failure surface.

- $\quad$ The factor of safety for all slides is equal.

- The failure surface does not pass below the toe of the wall.

From Figure 2,

$$
\begin{aligned}
& \sum F_{y}=0 \text { (for each slice) } \\
& V_{i+1}-V_{i}-W_{i}-q_{\mathrm{v} i}+S_{i} \sin \alpha_{i}+N_{i} \cos \alpha_{i}=0
\end{aligned}
$$

where $V_{i}$ and $V_{i+1}$ are the vertical interslice forces calculated by integration of overburden pressures on horizontal border of slice in a similar method to that used by Atkinson (1993) and Shahgholi et al. (2001).

Again,

$\tau_{\mathrm{r}}=\frac{\tau_{\mathrm{f}}}{\mathrm{FS}}$ (for each slice)

Thus

$$
\begin{aligned}
& S_{i}=\frac{1}{\mathrm{FS}}\left(c b_{i}+N_{i} \tan \phi\right) \\
& \sum F_{x}=0 \text { (for the whole wedge) }
\end{aligned}
$$

Considering $m$ layers,

$$
\sum_{j=1}^{m} t_{j}+\sum_{i=1}^{n} S_{i} \cos \alpha_{i}-\sum_{i=1}^{n} N_{i} \sin \alpha_{i}-\sum_{i=1}^{n} q_{\mathrm{h} i}=0
$$

Substituting for $S_{i}$ from Equation 13 into Equation 12,

$$
N_{i}=\frac{V_{i}-V_{i+1}+W_{i}+q_{\mathrm{v} i}-\left(c b_{i} / \mathrm{FS}\right) \sin \alpha_{i}}{(\tan \phi / \mathrm{FS}) \sin \alpha_{i}+\cos \alpha_{i}}
$$

$N_{i}$ is calculated using Equation 16, and $S_{i}$ is calculated using Equation 13. We can determine $t_{j}$ when FS is known.

The geosynthetic tensile reinforcement force $t_{j}$ required to maintain local stability for layer $j$ can be normalised to a parameter $K$, which is equivalent to the earth pressure coefficient

$$
K=\frac{\sum t_{j}}{0.5 \gamma H^{2}} \approx \frac{t_{j}}{\gamma h_{j} D_{j}}
$$


where $\gamma$ is the unit weight of the soil, and $D_{j}$ and $h_{j}$ are the tributary area and depth, respectively, of layer $j$.

For layer $j$ under consideration, the linear failure surface making an angle $\alpha_{i}$ with the horizontal is selected to give the maximum force, $t_{j}$ : that is, the required geosynthetic tensile reinforcement force $t_{j}$ for layer $j$ is optimised with respect to the failure surface angle $\alpha_{i}$. The search for the maximum forces is carried out using the Excel spreadsheet tool SOLVER.

The outermost critical multilinear failure surface obtained from the tieback analysis defines the active soil mass, as shown in Figure 1. It defines the boundary on which the geosynthetics anchor forces are applied so that an internally stable structure is produced. Each geosynthetic layer is extended into the stable backfill soil, i.e. tieback, so that the required geosynthetic tensile reinforcement force $t_{j}$ can be mobilised.

\subsection{Compound stability analysis}

Potential slip surfaces emerging beyond the outermost multilinear failure surface obtained in the tieback analysis, either outside or within the effective anchorage length, may not allow sufficient geosynthetic force to be mobilised, and hence may not provide adequate stability. Some layers may require a greater length of geosynthetic than that obtained from tieback analysis: that is, these layers are needed to resist possible compound failures in which the slip surfaces pass through both retained and reinforced soils. The geosynthetic layers are then anchored beyond all critical failure surfaces determined from tieback and compound stability analyses.

\subsection{Anchorage length}

The required anchorage length $l_{\mathrm{e}, j}$ for layer $j$ is determined as

$$
l_{\mathrm{e}, j}=\frac{t_{j}}{2 \sigma_{\mathrm{v}, j} C_{i} \tan \phi}
$$

where $C_{i}$ is the soil-geosynthetic pullout coefficient, expressed as the ratio of the soil-geosynthetic pullout strength to the soil strength (i.e. $\tan \phi$ ), $t_{j}$ is the required tensile resistance of layer $j$, and $\sigma_{\mathrm{v}, j}$ is the overburden pressure acting on the anchored portion of this layer.

The maximum length required to resist tieback and compound failure $\left(l_{\mathrm{c}}\right)$, can be normalised to parameter $L_{\mathrm{c}}$, which is equal to $l_{\mathrm{c}} / H$.

\section{RESULTS AND DISCUSSIONS}

\subsection{Parametric study}

To study the effects of pseudo-dynamic seismic inertia forces on the required geosynthetic strength and lengths, a parametric study was conducted on a reinforced soil wall with slope angle $\beta=90^{\circ}$, height $H=5 \mathrm{~m}$, unit weight of the soil $\gamma=18 \mathrm{kN} / \mathrm{m}^{3}$ and cohesion $c=0$, by considering 20 equally spaced geosynthetic layers. The soil-geosynthetic pullout coefficient $\left(C_{i}\right)$ is selected as 0.8 and the factor of safety (FS) is taken as 1.0 in the present analysis.

The results are presented in the form of tables and graphs. Variations of parameters considered in the present analyses are as follows.

- $\phi=20^{\circ}, 25^{\circ}, 30^{\circ}$

- $\quad k_{\mathrm{h}}=0.0,0.1,0.2,0.3$

- $\quad k_{\mathrm{v}}=0.0,0.5 k_{\mathrm{h}}$ and $1.0 k_{\mathrm{h}}$

- $V_{\mathrm{s}}=100 \mathrm{~m} / \mathrm{s}, V_{\mathrm{p}}=187 \mathrm{~m} / \mathrm{s}, H=5 \mathrm{~m}, T=0.3 \mathrm{~s}$, $H / \lambda=0.167, H / \eta=0.09, \beta=90^{\circ}$.

Table 1 shows the values of the required sum of geosynthetic tensile reinforcement force $\Sigma t_{j \max }$ for different values of $k_{\mathrm{h}}, k_{\mathrm{v}}$ and $\phi$. It is evident that the stability of the reinforced soil wall decreases as the values of $k_{\mathrm{h}}$ and $k_{\mathrm{V}}$ increase, thus showing that a greater $\Sigma t_{j \max }$ is required to maintain the stability of the wall.

\subsection{Effect of soil friction angle $\phi$ on normalised reinforcement force $K$}

Figures 3 and 4 show the effect of soil friction angle $\phi$ on the required normalised reinforcement force $K$ with $k_{\mathrm{h}}=$ 0.1 and 0.2 respectively. It can be seen that the required value of $K$ decreases with increase in $\phi$. For $k_{\mathrm{h}}=0.2$ and $k_{\mathrm{v}}=0.5 k_{\mathrm{h}}$, when $\phi$ changes from $20^{\circ}$ to $25^{\circ}$, the required value of $K$ decreases by about $19 \%$. Similarly, when $\phi$ changes from $25^{\circ}$ to $30^{\circ}$, the required value of $K$ decreases by about $22 \%$.

Table 1. Required sum of geosynthetic reinforcement layer forces $\left(\Sigma t_{j \max }\right)$ for different values of $k_{\mathrm{h}}, k_{\mathrm{v}}$ and $\phi$ with $\beta=90^{\circ}, H / \lambda=0.167, H / \eta=0.09$ and $H=5 \mathrm{~m}$

\begin{tabular}{|l|c|c|c|c|}
\hline \multirow{2}{*}{$k_{\mathrm{h}}$} & $k_{\mathrm{v}}$ & \multicolumn{3}{|c|}{ Required geosynthetic reinforcement, $\Sigma t_{j \max }(\mathrm{kN} / \mathrm{m})$} \\
\cline { 3 - 5 } & & $\phi=20^{\circ}$ & $\phi=25^{\circ}$ & $\phi=30^{\circ}$ \\
\hline 0.0 & 0.00 & 110 & 91 & 75 \\
0.1 & 0.00 & 137 & 113 & 93 \\
0.2 & 0.05 & 174 & 141 & 106 \\
& 0.10 & 226 & 175 & 126 \\
& 0.00 & 164 & 135 & 132 \\
0.3 & 0.10 & 211 & 169 & 164 \\
& 0.20 & 269 & 208 & 130 \\
& 0.00 & 196 & 160 & 156 \\
\hline
\end{tabular}

Geosynthetics International, 2006, 13, No. 3 


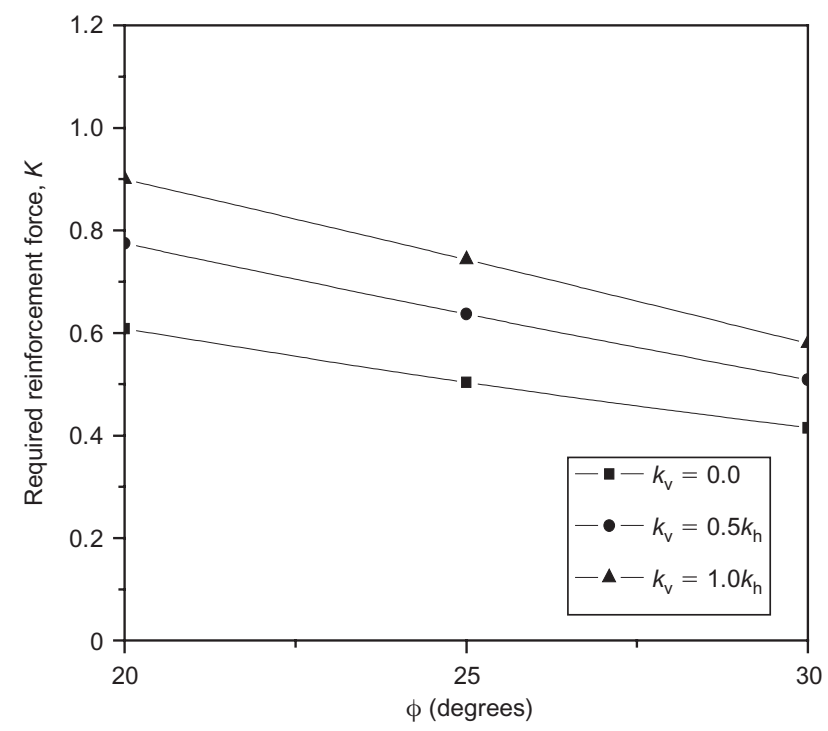

Figure 3. Required normalised geosynthetic tensile reinforcement force $(K)$ against soil friction angle at different seismic coefficients with $k_{\mathrm{h}}=0.1, H / \lambda=0.167, H / \eta=0.09, H=5 \mathrm{~m}$, $\beta=90^{\circ}$

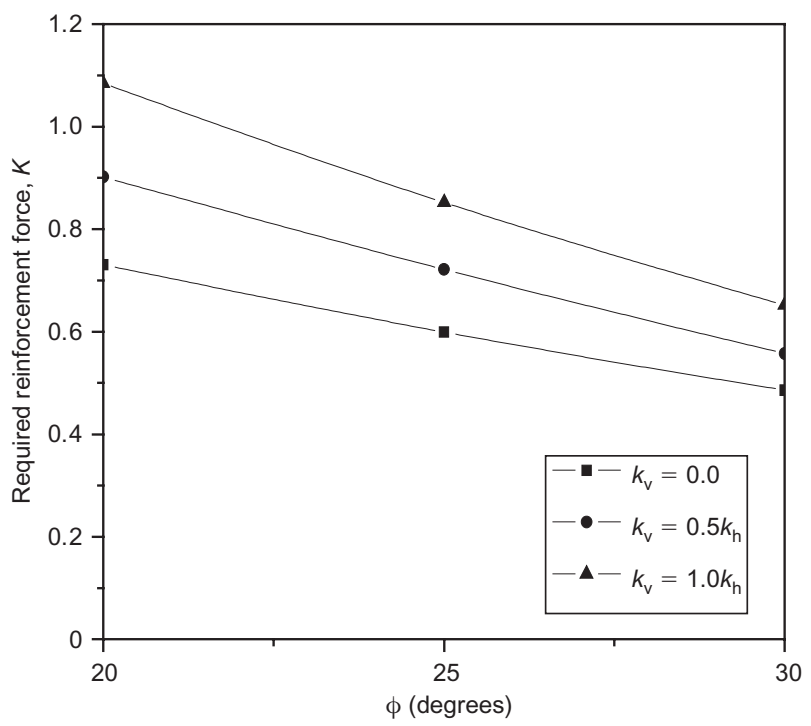

Figure 4. Required normalised geosynthetic tensile reinforcement force $(K)$ against soil friction angle at different seismic coefficients with $k_{\mathrm{h}}=0.2, H / \lambda=0.167, H / \eta=0.09, H=5 \mathrm{~m}$, $\beta=90^{\circ}$

\subsection{Effect of seismic acceleration coefficients $k_{\mathrm{h}}$ and} $k_{\mathrm{v}}$ on required normalised reinforcement force $K$

Figure 5 shows the effects of the horizontal and vertical seismic acceleration coefficients $k_{\mathrm{h}}$ and $k_{\mathrm{v}}$ on the required normalised reinforcement force $K$ for $\phi=30^{\circ}$. It is evident that the required value of $K$ shows a significant increase with increase in $k_{\mathrm{h}}$ and $k_{\mathrm{v}}$. Also, the rate of increase is less for higher seismic accelerations. For $k_{\mathrm{v}}=$ $0.5 k_{\mathrm{h}}$, when $k_{\mathrm{h}}$ changes from 0 to 0.1 , the required value of $K$ increases by about $41 \%$. When $\mathrm{k}_{\mathrm{h}}$ changes from 0.1 to 0.2 , the required value of $K$ increases by about $25 \%$, and when $k_{\mathrm{h}}$ changes from 0.2 to 0.3 , the required value of $K$ increases by about $18 \%$. For $k_{\mathrm{h}}=0.2$, when $k_{\mathrm{v}}$

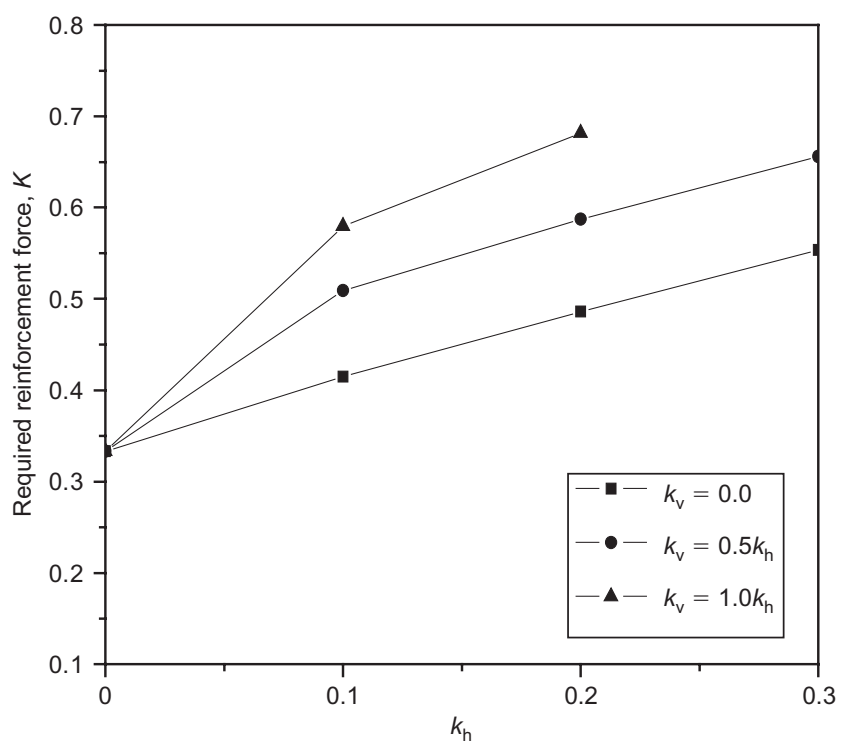

Figure 5. Effect of seismic coefficients on required geosynthetic tensile reinforcement force $(K)$ with $\phi=30^{\circ}$, $H / \lambda=0.167, H / \eta=0.09, H=5 \mathrm{~m}, \beta=90^{\circ}$

changes from 0 to $0.5 k_{\mathrm{h}}$, the required value of $K$ increases by about $21 \%$, and when $k_{\mathrm{v}}$ changes from $0.5 k_{\mathrm{h}}$ to $1.0 k_{\mathrm{h}}$, the required value of $K$ increases by about $24 \%$. Thus the effects of both $k_{\mathrm{h}}$ and $k_{\mathrm{v}}$ are significant in the computation of the required geosynthetic tensile reinforcement force as expressed by $K$.

\subsection{Effect of period of lateral shaking $T$ on required normalised reinforcement force $K$}

Figure 6 shows the effect of the period of lateral shaking $T$ on the required value of $K$ with $k_{\mathrm{v}}=0.5 k_{\mathrm{h}}, \phi=30^{\circ}$, $H=5 \mathrm{~m}$ and $\beta=90^{\circ}$. It can be seen that, for $k_{\mathrm{h}}=0.2$, the value of $K$ required to maintain stability of the reinforced-soil wall corresponding to $T=0.2 \mathrm{~s}$ is $3.9 \%$, $10.2 \%$ and $16.8 \%$ smaller than that corresponding to $\mathrm{T}=$

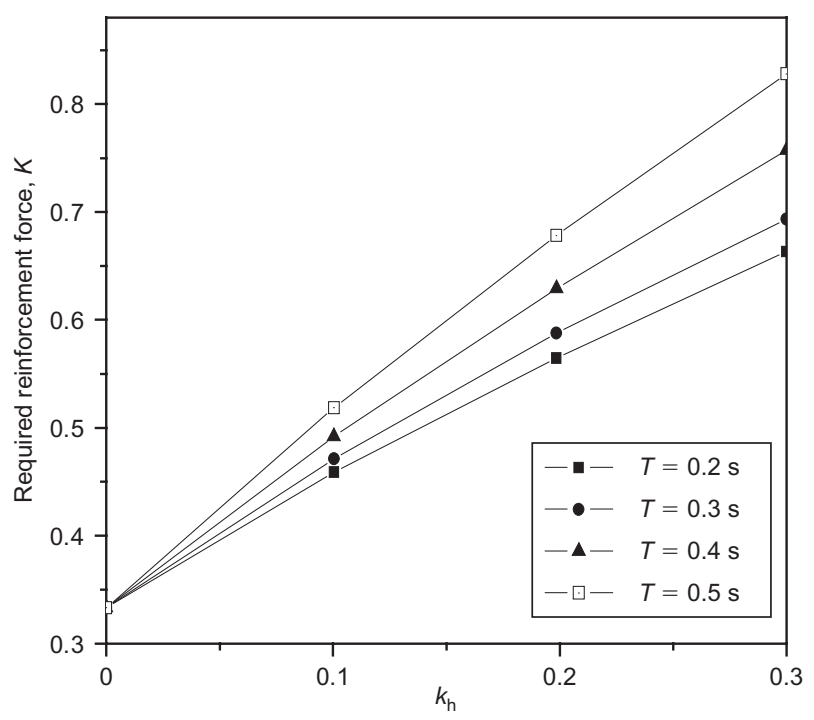

Figure 6. Effect of period of lateral shaking $(T)$ on required normalised geosynthetic tensile reinforcement force $(K)$ with $k_{\mathrm{v}}=0.5 k_{\mathrm{h}}, \phi=30^{\circ}, H=5 \mathrm{~m}, \beta=90^{\circ}$ 
$0.3 \mathrm{~s}, 0.4 \mathrm{~s}$ and $0.5 \mathrm{~s}$, respectively. Thus it is evident that, as $T$ increases, the seismic stability of the reinforced-soil wall decreases, requiring greater tensile reinforcement force. For most geotechnical structures $T=0.3 \mathrm{~s}$ is a reasonable value (Prakash 1981). Hence, for all other results reported in this paper, $T=0.3 \mathrm{~s}$ is used, and the results are expressed in terms of dimensionless parameters such as $H / \lambda=0.167$ and $H / \eta=0.09$.

\subsection{Effect of soil friction angle $\phi$ on required geosynthetic length $L_{\mathrm{c}}$}

Figures 7 and 8 show the effect of soil friction angle $\phi$ on the required geosynthetic length $L_{\mathrm{c}}$ with $k_{\mathrm{h}}=0.1$ and 0.2 , respectively. Again, as before, $H / \lambda=0.167, H / \eta=0.09$, $H=5 \mathrm{~m}$ and $\beta=90^{\circ}$. It can be seen that $L_{\mathrm{c}}$ decreases with increases in $\phi$. For $k_{\mathrm{h}}=0.2$ and $k_{\mathrm{v}}=0.5 k_{\mathrm{h}}$, when $\phi$ changes from $20^{\circ}$ to $25^{\circ}, L_{\mathrm{c}}$ decreases by about $53 \%$, and when $\phi$ changes from $25^{\circ}$ to $30^{\circ}, L_{\mathrm{c}}$ decreases by about $39 \%$. Thus the effect of soil friction angle is more pronounced on the required geosynthetic length than on the required geosynthetic tensile reinforcement force as expressed by parameter $K$.

\subsection{Effect of seismic acceleration coefficients $\boldsymbol{k}_{\mathrm{h}}$ and} $k_{\mathrm{v}}$ on required geosynthetic length $L_{\mathrm{c}}$

Figure 9 shows the effect of horizontal and vertical seismic acceleration coefficients $k_{\mathrm{h}}$ and $k_{\mathrm{v}}$ on the required geosynthetic length $L_{\mathrm{c}}$ with $\phi=30^{\circ}, H / \lambda=0.167, H / \eta=$ $0.09, H=5 \mathrm{~m}$ and $\beta=90^{\circ}$. It is evident that $L_{\mathrm{c}}$ shows an increase with increase in $k_{\mathrm{h}}$ and $k_{\mathrm{v}}$, and the rate of increase is less for higher seismic accelerations. For $k_{\mathrm{v}}=$ $0.5 k_{\mathrm{h}}$, when $k_{\mathrm{h}}$ changes from 0 to $0.1, L_{\mathrm{c}}$ increases by about $111 \%$; when $k_{\mathrm{h}}$ changes from 0.1 to $0.2, L_{\mathrm{c}}$ increases by about $64 \%$; and when $k_{\mathrm{h}}$ changes from 0.2 to $0.3, L_{\mathrm{c}}$ increases by about $62 \%$. Also, for $k_{\mathrm{h}}=0.2$, when $k_{\mathrm{v}}$ changes from 0 to $0.5 k_{\mathrm{h}}, L_{\mathrm{c}}$ increases by about $44 \%$, and when $k_{\mathrm{v}}$ changes from $0.5 k_{\mathrm{h}}$ to $1.0 k_{\mathrm{h}}, L_{\mathrm{c}}$ increases by

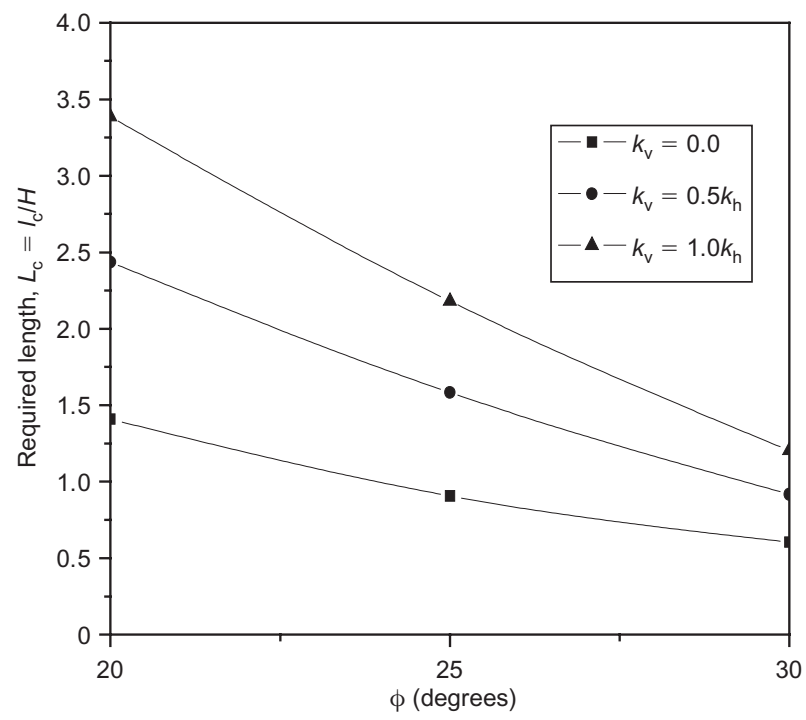

Figure 7. Required geosynthetic length $\left(L_{c}\right)$ against soil friction angle at different seismic coefficients with $k_{\mathrm{h}}=0.1$, $H / \lambda=0.167, H / \eta=0.09, H=5 \mathrm{~m}, \beta=90^{\circ}$

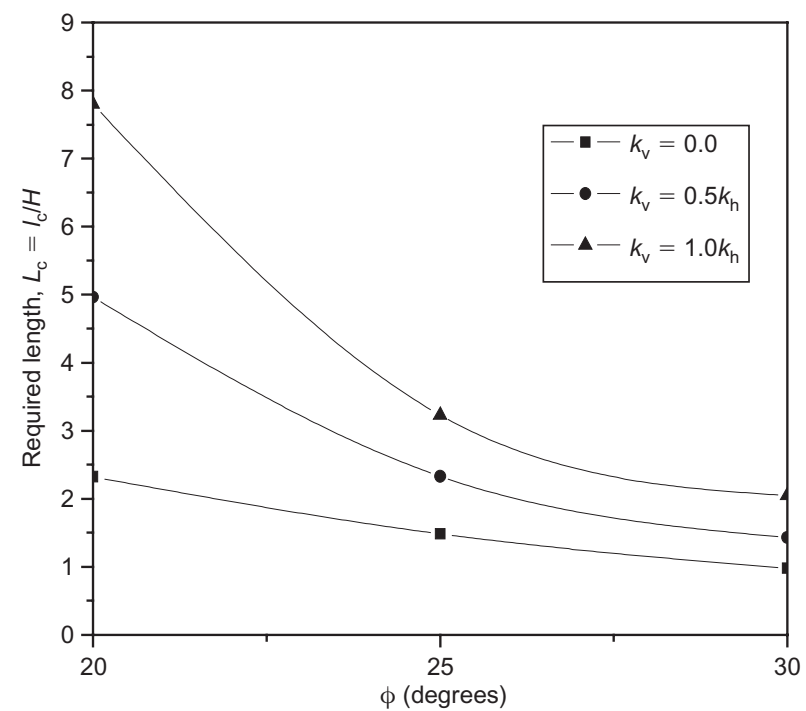

Figure 8. Required geosynthetic length $\left(L_{\mathrm{c}}\right)$ against soil friction angle at different seismic coefficients with $k_{\mathrm{h}}=0.2$, $H / \lambda=0.167, H / \eta=0.09, H=5 \mathrm{~m}, \beta=90^{\circ}$

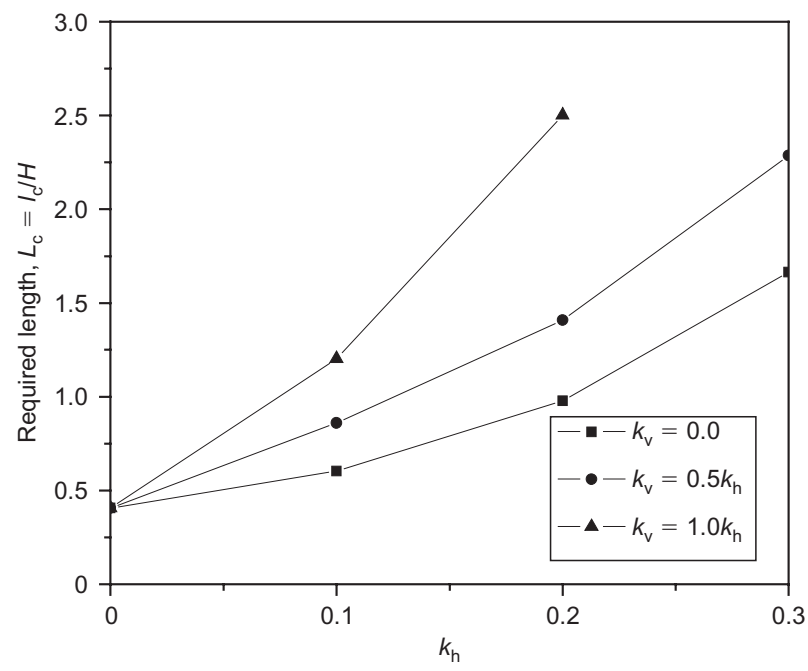

Figure 9. Effect of seismic coefficients on required geosynthetic length $\left(L_{\mathrm{c}}\right)$ with $\phi=30^{\circ}, H / \lambda=0.167, H / \eta=0.09$, $H=5 \mathrm{~m}, \boldsymbol{\beta}=\mathbf{9 0}{ }^{\circ}$

about $78 \%$. Thus the magnitudes of both the horizontal and vertical seismic acceleration coefficients have an important influence in the computation of the required length of the geosynthetic layer.

\subsection{Effect of period of lateral shaking $T$ on required geosynthetic length $L_{\mathrm{c}}$}

Figure 10 shows the effect of the period of lateral shaking $T$ on the required geosynthetic length $L_{\mathrm{c}}$ with $k_{\mathrm{v}}=0.5 k_{\mathrm{h}}$, $\phi=30^{\circ}, H=5 \mathrm{~m}$ and $\beta=90^{\circ}$. It can be seen that, for $k_{\mathrm{h}}=0.2$, the geosynthetic length $L_{\mathrm{c}}$ required to maintain stability of the reinforced-soil wall corresponding to $T=$ $0.2 \mathrm{~s}$ is $4.6 \%, 11.9 \%$ and $17.3 \%$ smaller than those corresponding to $T=0.3 \mathrm{~s}, 0.4 \mathrm{~s}$ and $0.5 \mathrm{~s}$, respectively. Thus it is evident from the plot that, as the period of lateral shaking increases, the seismic stability of the 


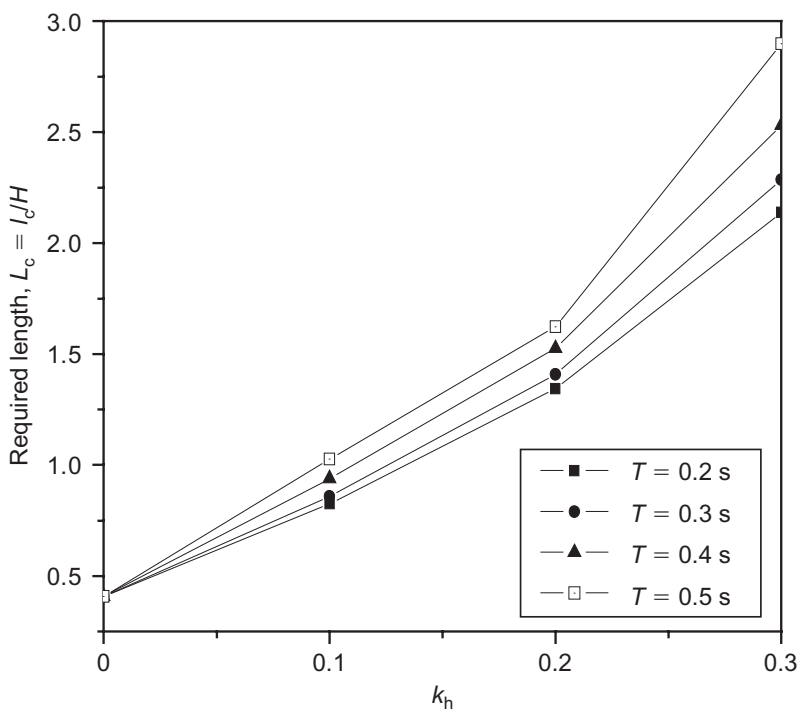

Figure 10. Effect of period of lateral shaking $(T)$ on required geosynthetic length $\left(L_{\mathrm{c}}\right)$ with $k_{\mathrm{v}}=0.5 k_{\mathrm{h}}, \phi=30^{\circ}, H=5 \mathrm{~m}$, $\boldsymbol{\beta}=90^{\circ}$

reinforced-soil wall decreases, requiring longer geosynthetic layers.

\section{COMPARISON OF RESULTS}

The pseudo-dynamic analysis of a typical reinforced soil wall by the method of horizontal slices has been presented and compared with the pseudo-static results using the method of horizontal slices proposed by Shahgholi et al. (2001) and the analytical model implemented in the program ReSlope by Leshchinsky (1997) and Ling et al. (1997). In the ReSlope program, the slip surface is assumed to be a log-spiral, whereas a multilinear slip surface is assumed both in the horizontal slice method proposed by Shahgholi et al. (2001) and in the present study. Table 2 shows the values of the required geosynthetic reinforcement force $\Sigma t_{j \max }$ for different values of $k_{\mathrm{h}}$ and $\phi$ with $\beta=90^{\circ}, k_{\mathrm{v}}=0.0, H /$ $\lambda=0.167, H / \eta=0.09$ and $H=5 \mathrm{~m}$. For $\phi=20^{\circ}$, when $k_{\mathrm{h}}$ changes from 0.0 to 0.1 , the required geosynthetic reinforcement force $\Sigma t_{j \max }$ calculated by the pseudo-dynamic method increases by $25 \%$, compared with $16 \%$ as computed by the pseudo-static method. For the static case, values using the analysis presented in this paper are exactly the same as those from Shahgholi et al. (2001), as expected. For the dynamic case, however, the pseudo-dynamic method originally proposed by Steedman and Zeng (1990) and further modified by Choudhury and Nimbalkar (2005, 2006) gives design values for required geosynthetic reinforcement strength and length by considering all probable dynamic factors in the design compared with the conventional pseudostatic approach. Also, in Table 3, the comparison of results for the required geosynthetic length $L_{\mathrm{c}}$ computed in the present study using pseudo-dynamic method with the pseudo-static results of Ling and Leshchinsky (1998) shows that the dynamic behaviour of a reinforced-soil wall system demands higher values of geosynthetic length than those obtained using the simplified pseudostatic method.

\section{CONCLUSIONS}

The seismic stability of reinforced soil walls has been investigated using a pseudo-dynamic method of analysis that incorporates the method of horizontal slices. The effects of various parameters on reinforced soil wall design, such as soil friction angle and horizontal and vertical seismic accelerations, have been shown. Phase change in both the shear and the primary waves propagating through the reinforced soil wall influences the design of the wall. The seismic stability of the reinforced soil wall reduces with increases in both $k_{\mathrm{h}}$ and $k_{\mathrm{v}}$. From the results of pseudo-dynamic analyses it is clear that both the horizontal and vertical seismic accelerations are important parameters for computation of the required length and tensile strength of the geosynthetic reinforcement, and, moreover, their importance increases as the earthquake intensity increases.

Table 3. Typical comparison of present results with pseudostatic results by Ling and Leshchinsky (1998)

\begin{tabular}{|l|c|c|}
\hline \multirow{2}{*}{$k_{\mathrm{v}}$} & \multicolumn{2}{|c|}{ Required length of geosynthetic layer, $L_{\mathrm{c}}$} \\
\cline { 2 - 3 } & $\begin{array}{c}\text { Method proposed by Ling } \\
\text { and Leshchinsky (1998) }\end{array}$ & Present study \\
\hline 0.0 & 0.818 & 0.978 \\
0.1 & 0.857 & 1.428 \\
0.2 & 0.912 & 2.046 \\
\hline
\end{tabular}

Data used: $k_{\mathrm{h}}=0.2, \phi=30^{\circ}, H / \lambda=0.167, H / \eta=0.09, H=5 \mathrm{~m}$, $\beta=90^{\circ}$.

Table 2. Typical comparison of present results with pseudo-static results by horizontal slice method (HSM) using method of Shahgholi et al. (2001) and results of ReSlope program by Leshchinsky (1997), Ling et al. (1997).

\begin{tabular}{|l|c|c|c|c|c|c|r|r|r|}
\hline \multirow{2}{*}{$k_{\mathrm{h}}$} & \multicolumn{9}{|c|}{ Required geosynthetic reinforcement, $\Sigma t_{j \max }(\mathrm{kN} / \mathrm{m})$} \\
\cline { 2 - 10 } & \multicolumn{3}{|c|}{$\phi=20^{\circ}$} & \multicolumn{3}{c|}{$\phi=25^{\circ}$} & \multicolumn{3}{c|}{$\phi=30^{\circ}$} \\
\cline { 2 - 11 } & ReSlope & HSM & Present study & ReSlope & HSM & Present study & ReSlope & HSM & Present study \\
\hline 0.0 & 110 & 110 & 110 & 95 & 91 & 91 & 74 & 75 & 75 \\
0.1 & 128 & 128 & 137 & 110 & 107 & 113 & 90 & 89 & 93 \\
0.2 & 151 & 151 & 164 & 126 & 127 & 135 & 106 & 106 & 109 \\
0.3 & 187 & 187 & 196 & 153 & 153 & 160 & 128 & 128 & 130 \\
\hline
\end{tabular}

Data used: $k_{\mathrm{v}}=0.0, H / \lambda=0.167, H / \eta=0.09, H=5 \mathrm{~m}, \beta=90^{\circ}$ 
With increases in the horizontal and vertical seismic accelerations, the required geosynthetic tensile strength and length increase. It is also evident from the analysis that the effect of soil friction angle and seismic horizontal and vertical accelerations on geosynthetic length is more pronounced than that on the tensile strength of the geosynthetic reinforcement. Comparisons presented in the paper with available pseudo-static methods yielded satisfactory agreement. Moreover, the present study shows that greater length and tensile strength of the geosynthetic reinforcement is required for safe design of geosynthetic-reinforced soil walls in earthquake-prone areas using a dynamic analysis as compared with conventional pseudo-static design methods.

\section{ACKNOWLEDGEMENTS}

The writers would like to thank the editor (R. J. Bathurst) and the anonymous reviewers of this technical paper for their valuable suggestions and comments, which have improved the final version.

\section{NOTATIONS}

Basic SI units are given in parentheses.

$a(z, t)$ acceleration at depth $z$, time $\left(\mathrm{m} / \mathrm{s}^{2}\right)$

$a_{\mathrm{h}}, a_{\mathrm{v}}$ amplitude of horizontal and vertical seismic acceleration $\left(\mathrm{m} / \mathrm{s}^{2}\right)$

$b_{j} \quad$ length of base of slice $(\mathrm{m})$

$c$ cohesion of soil $\left(\mathrm{N} / \mathrm{m}^{2}\right)$

$C_{i} \quad$ soil-geosynthetic pullout coefficient (dimensionless)

$D_{j} \quad$ tributary area for geosynthetic layer $j(\mathrm{~m})$

FS factor of safety (dimensionless)

$g$ acceleration due to gravity $\left(\mathrm{m} / \mathrm{s}^{2}\right)$

$G$ shear modulus of soil $\left(\mathrm{N} / \mathrm{m}^{2}\right)$

$h$ vertical distance between any point in soil mass and external borders of soil mass (m)

$H$ wall height (m)

$h_{j}$ depth of geosynthetic layer $j(\mathrm{~m})$

$K$ normalised geosynthetic tensile reinforcement force (equivalent earth pressure coefficient) (dimensionless)

$k_{\mathrm{h},} k_{\mathrm{v}} \quad$ seismic acceleration coefficient in horizontal and vertical directions (dimensionless)

$l_{\mathrm{c}}, l_{\mathrm{e}}$ geosynthetic lengths required to resist compound failure and pullout (m)

$L_{\mathrm{c}}, L_{\mathrm{e}}$ normalised geosynthetic lengths required to resist compound failure and pullout (dimensionless)

$m$ number of reinforcement layers (dimensionless)

$n$ number of slices (dimensionless)

$N_{i}$ normal force upon base of slice $(\mathrm{N} / \mathrm{m})$

$q_{\mathrm{h} i}, q_{\mathrm{v} i}$ horizontal and vertical inertia force due to seismic acceleration acting at layer $i(\mathrm{~N} / \mathrm{m})$

$S_{i} \quad$ shear force upon base of slice $(\mathrm{N} / \mathrm{m})$

$T$ period of lateral shaking (s)

$t$ time (s) $t_{j}$ required geosynthetic force in layer $j(\mathrm{~N} / \mathrm{m})$

$V_{\mathrm{p}}$ primary wave velocity $(\mathrm{m} / \mathrm{s})$

$V_{\mathrm{s}}$ shear wave velocity $(\mathrm{m} / \mathrm{s})$

$W_{i}$ weight of slice $(\mathrm{N} / \mathrm{m})$

$z_{j}$ depth from top of wall to top of horizontal slice $j$

$\alpha_{i}$ angle of base of elemental slice (degree)

$\beta$ slope angle (degrees)

$\gamma$ unit weight of soil $\left(\mathrm{kN} / \mathrm{m}^{3}\right)$

$\delta$ wall friction angle (degrees)

$\zeta \quad t-H / V_{\mathrm{s}}(\mathrm{s})$

$\eta \quad$ wavelength of the vertically propagating primary wave, $T V_{\mathrm{p}}(\mathrm{m})$

$\lambda$ wavelength of the vertically propagating primary wave, $T V_{\mathrm{s}}(\mathrm{m})$

$v$ Poisson's ratio (dimensionless)

$\rho$ density of soil $\left(\mathrm{kg} / \mathrm{m}^{3}\right)$

$\sigma_{\mathrm{v}}$ overburden pressure $\left(\mathrm{N} / \mathrm{m}^{2}\right)$

$\tau_{\mathrm{f}}$ failure shear stress $\left(\mathrm{N} / \mathrm{m}^{2}\right)$

$\tau_{\mathrm{r}}$ required shear stress $\left(\mathrm{N} / \mathrm{m}^{2}\right)$

$\phi$ soil friction angle (degrees)

$\psi \quad t-H / V_{\mathrm{p}}(\mathrm{s})$

$\omega$ angular frequency of base shaking $(\mathrm{rad} / \mathrm{s})$

\section{REFERENCES}

Atkinson, J. (1993). An Introduction to the Mechanics of Soils and Foundations. McGraw-Hill, London.

Choudhury, D. \& Nimbalkar, S. (2005). Seismic passive resistance by pseudo-dynamic method. Géotechnique, 55, No. 9, 699-702.

Choudhury, D. \& Nimbalkar, S. (2006). Pseudo-dynamic approach of seismic active earth pressure behind retaining wall. Geotechnical and Geological Engineering (in press).

Das, B. M. (1993). Principles of Soil Dynamics. PWS-Kent Publishing Company, Boston, MA.

Davies, T. G., Richards, R. \& Chen, K. H. (1986). Passive pressure during seismic loading. Journal of Geotechnical Engineering, ASCE, 112, No. 4, 479-484.

El-Emam, M. M. \& Bathurst, R. J. (2005). Facing contribution to seismic response of reduced-scale reinforced soil walls. Geosynthetics International, 12, No. 5, 215-238.

Huang, C. C. \& Wang, W. C. (2005). Seismic displacement charts for the performance-based assessment of reinforced soil walls. Geosynthetics International, 12, No. 4, 176-190.

Koerner, R. M. (1994). Designing with Geosynthetics, 3rd edn. Prentice Hall, Englewood Cliffs, NJ.

Kramer, S. L. (1996). Geotechnical Earthquake Engineering. Prentice Hall, Englewood Cliffs, NJ.

Kramer, S. L. \& Paulsen, S. B. (2004). Seismic performance evaluation of reinforced slopes. Geosynthetics International, 11, No. 6, 429-438.

Leshchinsky, D. (1997). ReSlope. Geotechnical Fabrics Report 15, No. 1, 40-46.

Leshchinsky, D. \& Boedeker, R. H. (1989). Geosynthetic reinforced earth structures. Journal of Geotechnical Engineering, ASCE, 115, No. 10, 1459-1478.

Ling, H. I. \& Leshchinsky, D. (1998). Effects of vertical acceleration on seismic design of geosynthetic-reinforced soil structures. Géotechnique, 48, No. 3, 347-373.

Ling, H. I., Leshchinsky, D. \& Perry, E. B. (1997). Seismic design and performance of geosynthetic-reinforced soil structures. Géotechnique, 47, No. 5, 933-952.

Ling, H. I., Mohri, Y., Leshchinsky, D., Burke, C., Matsushima, K. \& Liu, H. (2005). Large scale shaking table tests on modular-block reinforced soil retaining walls. Journal of Geotechnical and Geoenvironmental Engineering, ASCE, 131, No. 4, 465-476. 
Mononobe, N. \& Matsuo, H. (1929). On the determination of earth pressures during earthquakes. Proceedings of the World Engineering Congress, Tokyo, Vol. 9, pp. 177-185.

Prakash, S. (1981). Soil Dynamics. McGraw-Hill, New York.

Okabe, S. (1926). General theory of earth pressure. Journal of the Japanese Society of Civil Engineers, 12, No. 1.

Shahgholi, M., Fakher, A. \& Jones, C. J. F. P. (2001). Horizontal slice method of analysis. Géotechnique, 51, No. 10, 881-885.
Steedman, R. S. \& Zeng, X. (1990). The influence of phase on the calculation of pseudo-static earth pressure on a retaining wall. Géotechnique, 40, No. 1, 103-112.

Wright, S. G. \& Duncan, J. M. (1991). Limit equilibrium stability analysis for reinforced slopes. Transportation Research Record, No. $1330,40-46$.

Zeng, X. \& Steedman, R. S. (1993). On the behaviour of quay walls in earthquakes. Géotechnique, 43, No. 3, 417-431.

The Editors welcome discussion on all papers published in Geosynthetics International. Please email your contribution to discussion@geosynthetics-international.com by 15 December 2006. 